\title{
CONTROVÉRSIAS EM TORNO DAS IDENTIDADES PROFISSIONAIS DE LICENCIANDOS EM BIOLOGIA: UM ESTUDO INSPIRADO NA TEORIA ATOR-REDE
}

\author{
Luciana Resende Allain* \\ Universidade Federal dos Vales do Jequitinhonha e Mucuri (UFVJM), Diamantina - MG, Brasil \\ Francisco Ângelo Coutinho** \\ Universidade Federal de Minas Gerais (UFMG), Belo Horizonte - MG, Brasil
}

RESUMO: Este é um Estudo inspirado na Teoria Ator-Rede que buscou mapear a seguinte controvérsia envolvendo a identidade profissional de licenciandos em Ciências Biológicas: seriam as vivências formativas destes estudantes, de fato formativas, no sentido de construírem uma identidade com a profissão de professor? Em outras palavras, que disputas ocorrem em torno das identidades dos licenciandos no interior dos cenários formativos deles? Os dados foram coletados por meio de dois grupos focais com licenciandos formandos de uma grande universidade pública do sudeste brasileiro, a partir da metodologia da cartografia de controvérsias, referenciada pela Teoria Ator-Rede. Constatou-se que, ao longo da trajetória acadêmica dos licenciandos há composições de interesses (translações) que apresentam muito mais desvios que associações em relação à identidade docente, o que favorece a formação de uma extensa rede contraidentitária relativa à profissão de professor.

Palavras-chave: Identidade docente. Teoria Ator-Rede. Cartografia de controvérsias. Formação inicial de professores.

CONTROVERSIES AROUND THE PROFESSIONAL IDENTITIES OF UNDERGRADUATES IN BIOLOGY: A STUDY INSPIRED IN ACTOR-NETWORK THEORY

ABSTRACT: This is an study inspired in Actor-Network theory which sought to map the following controversy involving the professional identity of undergraduate on Biological Sciences: were the formative experiences of

\footnotetext{
"Doutora em Educação pela Universidade Federal de Minas Gerais (UFMG). Professora do curso de licenciatura em Ciências Biológicas da Universidade Federal dos Vales do Jequitinhonha e Mucuri (UFVJM). Grupos de pesquisa: Processos e Relações na Produção e Circulação do Conhecimento e Grupo de Pesquisa em Educação em Ciências, Matemática e Tecnologia. E-mail: luciana.allain@gmail.com "“ Licenciado em ciências biológicas, mestre em filosofia e doutor em educação, pela Universidade Federal de Minas Gerais. Professor da Faculdade de Educação da UFMG, onde atua na graduação e na pósgraduação. E-mail: < coutinhogambiarra@gmail.com>
} 
these students, in fact formative, in order to build an identity with teaching career? In other words, which disputes occur around the identities of these undergraduates within their formative scenarios? Data were collected through two focus groups with undergraduates from a large public university in southeastern Brazil, from the methodology of the mapping controversies, referenced by the Actor-Network Theory. It was found that, throughout the academic life of the undergraduates, there are interest compositions (translations) that presents much more deviations than associations in relation to teacher identity, which favors the formation of an extensive network against the teaching career.

Keywords: Teacher identity. Actor-Network Theory. Mapping controversies. Initial teacher training.

\section{INTRODUCุ̃̃O}

O objetivo deste artigo é apresentar um estudo sobre uma controvérsia envolvendo as identidades profissionais de professores de Biologia em formação. Tal estudo se inspira na Teoria Ator-Rede TAR - (LATOUR, 2012) e se propõe a seguir os rastros de um ator ${ }^{1} \mathrm{em}$ uma controvérsia e descrevê-los minuciosamente. Cada vez que um ator age, um rastro é produzido. Então, ao pesquisarmos as identidades dos licenciandos temos vários atores e rastros possíveis de serem escolhidos. Assim, escolhemos rastrear as vivências formativas dos licenciandos em Ciências Biológicas de uma grande universidade pública brasileira. Nosso propósito é incitar o debate acerca de uma controvérsia "quente": Seriam as vivências formativas dos licenciandos em Ciências Biológicas, de fato, formativas, no sentido de construírem uma identidade com a profissão de professor? Estas vivências formativas constroem no licenciando uma identidade como professor ou como biólogo?

Importante ressaltar que Latour (2015) atribui à expressão controvérsia uma gama muito ampla de aplicações, de modo que o mesmo termo pode abranger todo tipo de dissidência; dos desacordos entre pequenos grupos de cientistas altamente especializados até as questões públicas que mobilizam leigos na rua. Venturini (2010, p. 261) complementa: "controvérsias são situações nas quais os atores discordam (ou melhor, concordam em suas discordâncias)". E porque a identidade de licenciandos em Ciências Biológicas seria uma questão controversa? Não seria "natural", talvez até um tanto óbvio, pressupor que a licenciatura promove uma identidade com a profissão docente? Quem discordaria disso? O leitor verá, no entanto, que escolhemos mapear uma controvérsia quente, tendo em vista que o debate em torno das licenciaturas envolve disputas no campo 
acadêmico-técnico-científico, no campo político-econômico-social e impacta, direta ou indiretamente, a vida de milhares de pessoas. Além disso, esta é uma controvérsia bastante atual, uma vez que, neste exato momento, a discussão sobre a valorização do magistério tem tomado caráter de urgência e alcançado enormes proporções em nosso país, buscando inclusive envolver cada vez mais grupos e pessoas interessadas neste debate.

\subsection{DELINEANDO A CONTROVÉRSIA EM TORNO DAS IDENTIDADES DE LICENCIANDOS EM BIOLOGIA}

Vários estudos vêm sendo desenvolvidos no Brasil abordando o processo de formação de professores de Biologia. Entre os trabalhos que analisam questões relacionadas aos cursos de Biologia e aos estudantes desse curso, Diniz Pereira (2000), Araújo et al. (2007); Cerqueira e Cardoso (2010); Castro, Brandão e Nascimento (2011); Araújo e Viana (2011); Rocha (2013) apontam que o Curso de Licenciatura em Biologia para muitos estudantes é uma via de acesso fácil a outros cursos de maior prestígio social, em função de não terem sido aprovados no curso almejado. Além disso, outro aspecto preocupante é que os estudantes apresentam uma significativa propensão a atuação na área da pesquisa biológica e um alto índice de rejeição a atuação na docência. Isso contraria a ideia inicial de que, por cursarem uma licenciatura - modalidade voltada para a formação de professores - estes estudantes estariam interessados na carreira docente. O que se observa, segundo apontam os estudos, é um direcionamento dos próprios cursos para os estudantes atuarem em outras áreas da Biologia. Estes trabalhos também mostram que entre aqueles acadêmicos que querem atuar na docência, grande parte se sente mais atraída pelo Ensino Superior e não pela atuação na Educação Básica, nível de ensino para o qual estão sendo formados.

Esta situação evidencia que os licenciandos em Ciências Biológicas têm encontrado muitas dificuldades em construir uma identidade com a docência. Em acréscimo, argumentamos que muitos cursos de licenciatura em Biologia acabam por forjar aquilo que aqui denominamos de "contraidentidade" docente, na medida em que se desenha como perfil do egresso destes cursos um profissional que possa assumir múltiplas funções, inclusive a docência, e não prioritariamente a docência, como seria o esperado para um curso de licenciatura. Embora concordemos com Pimenta (2005) sobre o caráter pessoal e idiossincrático da construção da identidade docente, entendemos também que esta mesma identidade docente vai se constituindo ao longo das experiências de formação do professor, dentre as quais a 
graduação ocupa lugar de destaque. Entendemos que a licenciatura oferece um espaço-tempo de construção de "um conjunto de conhecimentos, habilidades, atitudes, valores que definem e orientam a especificidade do trabalho do professor" (LIBÂNEO, 2001, p. 68), contribuindo para a constituição de uma dada identidade.

Ora, se a licenciatura é (ou deveria ser) um espaço-tempo de vivências formativas, isto é, um lugar e um momento fundamentais para a construção das identidades docentes, por que os licenciandos em Ciências Biológicas não almejam ser professores da Educação Básica? Que disputas ocorrem no interior dos cenários formativos destes licenciandos, em torno de suas identidades? Que atores e que interesses estão em jogo nestas disputas? Esta é a controvérsia que vamos explorar neste artigo.

\section{A CARTOGRAFIA DE CONTROVÉRSIAS COMO METODOLOGIA PARA MAPEAR DISPUTAS}

A cartografia de controvérsias foi concebida como um conjunto de ferramentas capaz de seguir disputas que cruzam fronteiras disciplinares e de lidar com a crescente hibridização entre humanos e coisas (VENTURINI, 2010). Por isso, nos inspiramos na cartografia de controvérsias para mapear as disputas em torno das identidades profissionais dos estudantes de licenciatura em Ciências Biológicas.

Latour (2015) ensina que, para explorar a riqueza das controvérsias sem se perder em sua complexidade, é útil desenhar mapas. Não só mapas geográficos, mas todo tipo de inscrição que permita visualizar as alianças e oposições entre atores e ideias ativos em uma disputa. Como é impossível reduzir a complexidade de uma controvérsia em um único mapa ou inscrição, é importante desdobrála e depois reconstruí-la por meio de uma cadeia de representações subsequentes. Segundo Latour (2015), o mapeamento de controvérsias permite abrir as caixas-pretas das disputas científicas, seguir seus atores e desvendar seus imbróglios. Além disso, permite que possamos fechar controvérsias, formarmos uma opinião e decidirmos quais atores exigem nossa vigilância e quais merecem nosso apoio.

De acordo com Venturini et al. (2015), para mapear controvérsias é necessário confeccionar uma espécie de atlas. Para a composição deste atlas de mapas da controvérsia é necessário lançar mão de algumas lentes de observação. Mais do que um guia metodológico, elas buscam focar nossa visão nas diferentes camadas da controvérsia. A primeira lente levanta o questionamento: Sobre o que é a controvérsia? Ao responder esta questão, delineamos a 
controvérsia, passando dos argumentos (caoticamente esparsos na literatura e aparentemente isolados entre si) para o debate (quando articulamos os argumentos das vozes dissonantes). A segunda lente de observação busca responder ao questionamento: Quem são os atores envolvidos na controvérsia? Nesta lente vamos do debate aos atores (também chamados de actantes). Identificamos quem está agindo no contexto da controvérsia - quer seja este ator uma pessoa, uma organização, uma coisa, um animal, uma entidade, uma lei, e assim por diante. A terceira lente de observação trata de responder à pergunta: como os atores estão conectados? Vamos, então, dos atores às redes. Os atores, assim como os argumentos, nunca estão isolados nas controvérsias, ao contrário; suas identidades são definidas a partir de alianças e oposições a determinados grupos. Atores são compostos por redes e, simultaneamente, componentes delas. Esta lente destinase a visualizar estas conexões e os movimentos de individualização e aglutinação que caracterizam as controvérsias. A quarta lente de observação traz o questionamento: onde a controvérsia acontece? Toda controvérsia é parte de outra controvérsia maior, uma espécie de metacontrovérsia e também é composta por outras subcontrovérsias menores. Como pesquisadores, somos livres para escolher nossa escala de investigação, mas devemos ser capazes de situá-la na "escala de disputas" a qual ela pertence (VENTURINI et al., 2015). Nesta camada, passamos das redes aos cosmos. A última lente de observação busca responder: quando a controvérsia acontece? Segundo os autores, esta última lente é certamente a mais difícil. Além de apresentar sobre o que é a controvérsia, quais são os embates, como os atores se conectam ou se opõem e onde as batalhas acontecem, cartógrafos também devem mostrar como todos estes elementos evoluem ao longo do tempo. Adicione a isso o fato de que o tempo de controvérsias é muitas vezes heterogêneo, já que diferentes partes da mesma controvérsia podem permanecer dormentes por tempos e de repente explodirem em desenvolvimentos mais rápidos. Assim, vamos dos cosmos às cosmopolíticas.

Neste artigo, descreveremos os cosmos performados no debate sobre as identidades docentes dos licenciandos em Ciências Biológicas. Para isso, elaboramos inscrições na forma de redes e diagramas, que sintetizam o inventário dos atores envolvidos na controvérsia, o modo como estão conectados e o movimento destes nas redes, isto é, as translações de interesse na rede identitária docente. Até aqui já delineamos a controvérsia. Passemos a explorar outros mapas que compõem o atlas do mapeamento. 


\subsection{ONDE E QUANDO A CONTROVÉRSIA SE PASSA? - A ESCOLHA DO CAMPO DE INVESTIGAC̣̃̃O}

A controvérsia que mapeamos envolveu um curso de licenciatura em Ciências Biológicas de uma grande universidade pública do Sudeste do Brasil. O estudo aconteceu durante o segundo semestre de 2013, quando os licenciandos deste curso estavam em vias de se formar. Esclarecemos que por questões éticas seguimos as orientações da TAR no que diz respeito à participação dos licenciandos neste estudo. Mais do que meros sujeitos de pesquisa, Latour esclarece que é necessário que "se permita aos atores manifestarem seus próprios e diversos cosmos, por mais contra-intuitivos que eles pareçam (LATOUR, 2008, p. 43). Neste sentido, o exercício de ouvir os licenciandos sem julgamento de valores sobre suas percepções, impressões e opiniões nos proporcionou aprendermos a ser afetados (LATOUR, 2008, p. 39) por suas vozes, por suas falas.

Como as redes são fluidas e instáveis, este trabalho pode ser entendido como um retrato, uma espécie de fotografia da realidade que observamos em um determinado momento. Então, a finalidade deste trabalho não é generalizar as análises, mas compreender a rede identitária que foi se constituindo a partir destes dados, bem localizados temporal e sociomaterialmente.

\subsection{ABRINDO A CAIXA DE FERRAMENTAS: O PERCURSO METODOLÓGICO}

A cartografia de controvérsias recusa-se a se filiar a um único protocolo metodológico, antes disso, encoraja os pesquisadores a realizar uma verdadeira "promiscuidade" de métodos (VENTURINI, 2010). Neste sentido, fazendo uma analogia com os trabalhos manuais, para mapear a controvérsia envolvendo as identidades docentes, buscamos abrir nossa caixa de ferramentas e escolhemos aquelas que nos pareceram mais adequadas para cada trabalho. Neste artigo, apresentaremos dados coletados por meio de dois grupos focais. Segundo Barbour (2009), entrevistas com grupos focais são adequadas a estudos que buscam entender atitudes, preferências, necessidades e sentimentos individuais e entre grupos. Para identificar os actantes nas narrativas dos sujeitos nos baseamos em alguns aspectos da análise de conteúdo (MORAES, 1999).

\section{QUEM SÃO OS ATORES DA DISPUTA E COMO ESTÃO CONECTADOS?}

As análises a seguir referem-se à composição do atlas de mapeamento da controvérsia: a identificação de actantes que promovem desvios e associações quanto à identidade docente, 
ao longo da trajetória do curso, relatada pelos licenciandos no decorrer dos grupos focais. Para permitir uma leitura mais fluida organizamos o relato a partir de três momentos distintos da trajetória dos licenciandos. Um primeiro momento se refere aos actantes apontados nos depoimentos deles, que agiram na rede identitária no período anterior à entrada no curso; um segundo momento se refere aos actantes elencados pelos sujeitos, que agiram na época da entrada no curso propriamente dita; e um terceiro momento refere-se aos actantes que agiram durante a trajetória acadêmica dos licenciandos. Todos os actantes identificados serão sublinhados neste texto.

\subsection{ATORES QUE AGIRAM NA REDE IDENTITÁRIA ANTES DA ENTRADA NO CURSO}

Iniciamos o grupo focal com uma questão "quebra gelo" que tinha a intenção de deixar os sujeitos mais à vontade para emitirem suas opiniões. Perguntamos a eles porque escolheram fazer Biologia. Vários sujeitos apontaram a influência de seus professores das escolas da Educação Básica na escolha por esse curso. Curiosamente, alguns deles apontaram a influência dos professores da Educação Básica na escolha pela docência, embora este não tivesse sido o foco inicial da nossa pergunta. Os trechos abaixo ilustram isso:

na verdade eu decidi ser professora/ especialmente/ assim/ por que eu tive bons
professores/ eu adorava/ era muito bacana a maneira como eles davam aula.
(...) Tinha um professor/ ou professora/ eu nem lembro/ é engraçado como eu
tenho uma memória muito boa desse professor/ mas eu nem sei se era mulher/
se era homem/ o que era/ não lembro/ só sei que ele fez um viveiro/ com uma
cobra/ aquelas cobrinhas d'água/ a cobra tinha nome/ a turma ficou maluca/
eu adorei aquilo/ falei/ ah/ é isso que eu vou ser/ desde isso/ aí eu quis já ser
professora de ciências/ por que foi muito legal. (Elisa)

Conforme se vê nas falas acima, os professores da Educação Básica tiveram um papel decisivo na escolha destes licenciandos pela profissão de professor. Por isso são actantes que agiram na rede identitária, se associando à identificação dos licenciandos com a docência.

Outro actante, híbrido, que identificamos na fala dos licenciandos são as experiências escolares que eles vivenciaram enquanto estudantes da Educação Básica. Veja alguns exemplos:

(...)/ e um (professor) também que fez um joguinho com a gente que era o jogo do milhão das ciências/ e aquilo também me deixou muito feliz. (Zélia)

Ela disponibilizou material didático próprio/ ela levava data show para a sala de aula/ transparência/ coisa que eu nunca tinha visto na minha vida/ e eu comecei a me dar bem no conteúdo dela/ eu comecei/ passei a gostar/ então assim/ essa professora que é responsável por eu estar fazendo Biologia. (Ester) 
Poderíamos supor que estas experiências são apenas os efeitos da atuação dos professores. Afinal, é preciso alguém (um sujeito) para desenvolver tais experiências. No entanto, do ponto de vista da TAR elas são mediadores, pois transformam/deslocam os interesses dos sujeitos, em vez de funcionarem como meros intermediários dos conteúdos. Isso fica claro quando Elisa afirma: "eu nem sei se era mulher/ se era homem/ o que era/ não lembro/ só sei que ele fez um viveiro/ com uma cobra/ aquelas cobrinhas d'água/ a cobra tinha nome/ a turma ficou maluca/ eu adorei aquilo/ falei/ ah/ é isso que eu vou ser".

Note que Elisa chama atenção para os objetos e as experiências propriamente (cobras d'água, fazer o viveiro), e não para os professores que as realizaram. Ela sequer lembra quem era o professor ou a professora. Como deslocaram os interesses dos sujeitos, as experiências agiram na rede identária docente, por este motivo são consideradas aqui como um actante.

Identificamos, portanto, translações que se associaram à rede identitária docente antes mesmo da entrada dos licenciandos no curso. Entretanto, seus depoimentos também mostram que ocorreram translações que desviaram o interesse pela docência antes de ingressarem na licenciatura. É o caso, por exemplo, das suas percepções sobre a docência. Referências ao magistério como uma atividade desprestigiada e mal remunerada, bem como de uma profissão socialmente importante e útil estiveram presentes na fala dos sujeitos. Estas percepções, positivas e negativas, da atividade do professor, tanto desviam quanto se associam ao fortalecimento da identidade docente e marcam a trajetória de escolha pela licenciatura. Observe as falas abaixo que ilustram estas percepções:

\footnotetext{
Ser professor hoje não é legal como era/ sei lá/ vinte/ cinquenta/ sei lá quantos anos atrás/ quando ser professor era autoridade de sala/ tinha poder aquisitivo/ por questão social da época./ Então assim/ já no seu ingresso/ você fala/ "eu estou fazendo licenciatura/ vou ser professor/ ah tá. (Elisa)

Que dó! (Zélia)
}

Nestas falas observamos que as percepções dos licenciandos sobre a docência são figurações que acionam experiências e imagens de outros tempos e espaços. Como nos lembra Nespor (1994), as nossas vivências aqui e agora são mediadas por pessoas e coisas de outros lugares e épocas. Isso fica claro na fala de Elisa, quando ela diz: "Ser professor hoje não é legal como era/ sei lá/ vinte/ cinquenta/ sei lá quantos anos atrás/ quando ser professor era autoridade de sala/ (e) tinha poder aquisitivo". Então, não podemos desconsiderar que a 
construção da identidade profissional pelos licenciandos é resultado de actantes distribuídos em um vetor espaço-temporal.

A representação gráfica que segue ilustra a rede identitária docente antes do ingresso dos licenciandos no curso. Note que os actantes representados à esquerda se associam à construção de uma identidade com a docência, ao passo que o ator em negrito simboliza um desvio desta identidade.

FIGURA 1 - Actantes que agem na rede identitária docente antes do ingresso dos licenciandos no curso de licenciatura

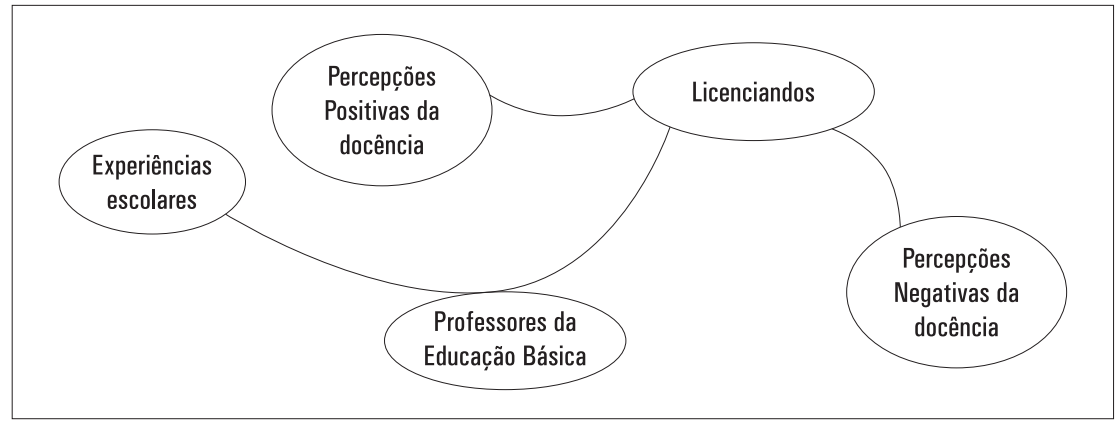

\subsection{ATORES QUE AGIRAM NA REDE IDENTITÁRIA NO MOMENTO DO INGRESSO NO CURSO}

Dando continuidade ao grupo focal perguntamos aos licenciandos quais eram suas expectativas profissionais quando entraram no curso. Surpreendentemente percebemos que muitos deles não tinham uma expectativa construída no momento da escolha pelo curso de graduação. A oferta do curso no período noturno, a possibilidade de conciliar trabalho no período diurno e estudo durante a noite e a baixa concorrência na modalidade licenciatura foram argumentos comumente utilizados para justificar o ingresso na graduação.

Veja isso nos seguintes exemplos:

Quando eu fiz orientação vocacional de novo/ eu cheguei a conclusão/ já que eu trabalhava de dia/ que/ é/ chegou essa conclusão do curso de Biologia/ já tinham poucos cursos noturnos/ o conteúdo me interessava/ e aí eu pensei: Vou fazer Biologia. (Efigênia)

Eu sabia muito bem a diferença (entre bacharelado e licenciatura)./ Eu escolhi a licenciatura porque eram/ sei lá/ oito candidatos por vaga em 2009/ e/ o bacharelado era dobrado. (Samanta)

De uma maneira geral, os exemplos supracitados reforçam que, para boa parte dos licenciandos, ingressar em um curso de formação de professores não foi propriamente uma escolha, mas uma decisão oportuna (e porque não, oportunista), tendo em vista a facilidade de 
acesso ao ensino superior proporcionado pela modalidade licenciatura e pelo curso noturno, menos concorridos que o curso de bacharelado, oferecido no período diurno. A modalidade licenciatura e o curso noturno são, portanto, actantes que, no momento da entrada no curso, agem, facilitando a entrada em um curso superior. $O$ efeito desta agência é uma translação que se desvia da identidade com a profissão docente.

No entanto, houve um caso em que a oferta da licenciatura em um curso noturno possibilitou a concretização do desejo de ser professor, pois possibilitou à licencianda conciliar os momentos de trabalho e estudo. Portanto, neste caso, os mesmos actantes curso noturno e modalidade licenciatura realizam uma translação que se associa ao fortalecimento da identidade docente. Veja isso a seguir: (Quanto a) questão do ingresso/ quando eu entrei/ eu trabalhava/ então (por isso)/ a escolha do noturno:/ eu já queria mesmo/ ser professora/ para mim nunca foi problema/ então só uniu o útil ao agradável. (Elisa)

Uma possível representação gráfica que ilustra os actantes que agiram no momento do ingresso no curso seria a que segue na Figura 2:

FIGURA 2 - Actantes que agem na rede identitária docente no momento do ingresso no curso de licenciatura

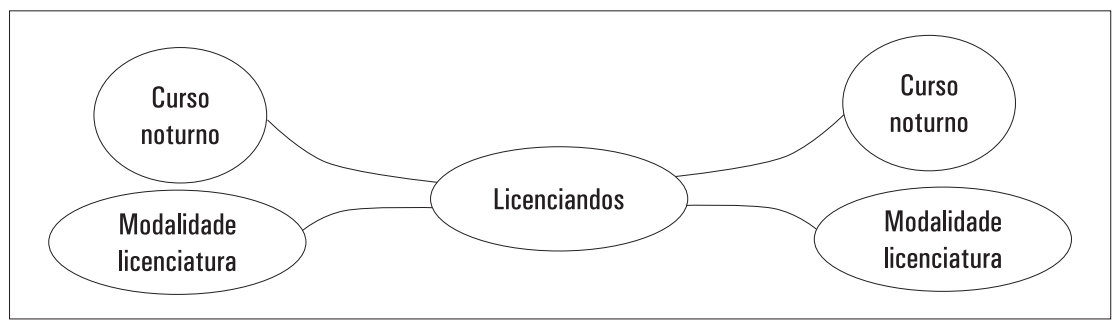

Observe que nesta rede os mesmos actantes realizam translações que se associam (representados à esquerda) e que desviam (representados em negrito) o interesse dos licenciandos pela docência no momento do ingresso no curso. Então, nos perguntamos: em relação à nossa pesquisa, que actantes agiram no decorrer da formação acadêmica dos licenciandos no sentido de favorecer ou dificultar a identidade com a profissão docente? O próximo tópico trata disso.

\subsection{ATORES QUE AGIRAM NA REDE IDENTITÁRIA DURANTE A TRAJETÓRIA ACADÊMICA}

Dando sequência ao grupo focal os licenciandos iniciaram espontaneamente uma avaliação da formação para a docência, apontando problemas no currículo da licenciatura e nos espaços formativos da universidade, em especial o Instituto de Ciências Biológicas (ICB), onde recebem toda a formação dos conteúdos 
específicos da Biologia, e a Faculdade de Educação (FaE), onde têm contato com os conteúdos pedagógicos. Ao se referirem ao ICB, os licenciandos afirmam:

O ICB é voltado muito mais para a área de pesquisa/ e os professores te incentivam muito mais à área de pesquisa. (Zélia)

O ICB é pesquisa. (Efigênia)

$\mathrm{Na}$ verdade/ desde o início/ fazer o bacharelado é mais legal [ela faz gesto de entre aspas]/ tem assim essa atmosfera/ não só pelos professores lá do ICB/ como tudo/ por causa da depreciação que o status de professor perdeu. (Elisa)

Podemos perceber pelas falas que o ICB, bem como os seus professores, direciona os licenciandos mais à pesquisa na área biológica que à docência. Verificamos, portanto, uma translação que desvia os licenciandos da identidade docente uma vez que, por ser um curso de licenciatura, a docência deveria ser estimulada. Evidentemente, este desvio nem sempre é explícito; por exemplo, numa perspectiva da TAR, para muitos professores do ICB é interessante estender sua própria rede de estudos e pesquisas, e, por este motivo, a fala de Zélia nos parece emblemática: "os professores te incentivam muito mais à área de pesquisa". Elisa completa que a "atmosfera" favorece o bacharelado.

Ao nos referirmos ao ICB, percebemos uma extensa rede, em que estão envolvidos não apenas os professores deste instituto e os licenciandos, mas também híbridos, tais como a formação dos formadores de professores, os laboratórios de pesquisa, seus financiamentos, o currículo do curso e assim por diante. Por este motivo, consideraremos o $\underline{\mathrm{ICB}}$ como um ator-rede ${ }^{2}$.

Um dos actantes que compõem o ator-rede ICB é o currículo do curso de licenciatura. Durante o grupo focal, uma licencianda chama atenção, em vários momentos, para a necessidade de uma formação específica para a licenciatura. Veja um dos trechos de sua fala:

Eu acho que como o curso é voltado para licenciatura/ tinha que ter uma formação diferenciada/ o curso/ então/ ele não é diferenciado/ bacharelado e a licenciatura. Tem diferença de algumas disciplinas/ mas as disciplinas que têm em comum ela não é diferenciada para quem faz licenciatura (...) Eu/ sinceramente eu acho que precisava de ter uma mudança nesse sentido/ eu continuo tendo essa visão/ que poderia sim ter uma forma de estimular quem faz licenciatura a realmente continuar na licenciatura./ Ele escolheu a fazer licenciatura/ estava escrito lá/ "licenciatura" / ele foi porque ele quis/ ninguém o obrigou/ então o curso devia ter uma grade voltada realmente [para isso]. (Zélia)

O currículo, portanto, também pode ser elencado como um ator que realiza translações que desviam o interesse pela docência, uma vez que ele não oferece uma formação específica para professores. 
Outros licenciandos argumentam, por sua vez, que os conteúdos biológicos devem ser lecionados da mesma forma para ambas as habilitações: licenciatura e bacharelado.

Na minha concepção/ esse conteúdo que não é da educação ser o mesmo tanto para bacharel quanto para licenciado/ é que isso não te limita à carreira acadêmica de professor. (Ester)

Conforme se vê, a formação dicotômica - entre conteúdos biológicos e pedagógicos - é defendida por estes licenciandos como uma "garantia" de que sua formação biológica não seria diferente de um bacharelando. Vemos que aqui também está sendo performada uma translação pelos licenciandos, pois esse interesse se dá em função da possibilidade de um "aproveitamento" dessas disciplinas para a complementação numa possível formação em bacharelado.

Os licenciandos passam a tecer duras críticas às disciplinas de Laboratório de Ensino, que são lecionadas pelos professores do ICB. Os sujeitos afirmam que boa parte dos professores destas disciplinas não tem a formação para a docência, apesar de se encontrarem na condição de formadores de professores. Identificamos, portanto, os professores formadores e os Laboratórios de Ensino como actantes que fazem parte do ator-rede ICB e que desviam o interesse dos licenciandos pela docência. A falta de formação dos professores formadores é figurada pelos professores, ou seja, atua através deles, também desviando o interesse dos licenciandos pela docência. Veja isso no exemplo a seguir:

Porque eu acho que os professores dos Laboratórios de Ensino/ não têm nenhuma orientação pedagógica para programar a disciplina/ a minha professora do Laboratório de Ensino de patologia era/ médica veterinária/ (...) tem que ter uma orientação com um profissional de educação/ lá/ para eles programarem uma disciplina que é sobre educar nesse tema. (Samanta)

A fala acima, somada àquelas que apresentamos nas páginas anteriores, mostra que grande parte dos professores do ICB desvia o interesse dos alunos pela licenciatura. Quando os licenciandos dizem que "O ICB é pesquisa" e que "os professores te incentivam muito mais à área de pesquisa", reconhecemos nestes professores os porta-vozes de um grupo hegemônico no ICB, que chamaremos de Grupo contra docência. Também estão neste grupo os professores que não colocam a docência como objetivo prioritário do curso de licenciatura e que estimulam a formação de um profissional "dois em um". Observe o que diz um dos licenciandos:

$\mathrm{Na}$ época a coordenadora do curso falou que não/ que o biólogo licenciado é um biólogo como um bacharel/ com essa diferença de poder dar aula/ e você pode fazer o mestrado do mesmo jeito/ (...) aí quando eu parei para decidir eu falei assim "legal/ então eu posso ao invés de fazer o bacharelado/ já que eu tenho o 
diferencial de ser / né/ licenciado para dar aula/ se eu quiser eu faço o mestrado" / e/ na época era isso. (Ronaldo)

No extrato destacado acima, a coordenação do curso aparece como um ator que desvia os licenciandos de uma identidade com a profissão de professor. Neste episódio identificamos as táticas de uma translação que está: 1) deslocando objetivos (a docência não é o objetivo prioritário), 2) oferecendo novos objetivos (licenciados podem complementar sua formação se não quiserem ser professores), 3) inventando novos grupos (de um profissional "dois em um") e 4) tornando invisível o desvio (licenciados tem o "diferencial" de poder dar aula).

O baixo status da licenciatura em relação ao bacharelado e da docência em relação à pesquisa faz da isonomia profissional dos biólogos licenciados e bacharéis uma suposta solução para a baixa atratividade da licenciatura. A percepção dos licenciandos é que, cursando a licenciatura, estarão em vantagem, pois além de poderem atuar como biólogos, podem também dar aulas. No entanto, esta é uma falsa valorização da profissão docente, uma vez que, na concepção dos sujeitos, o licenciado é um biólogo que tem o "diferencial" de poder dar aula, se quiser. Podemos ver isso no trecho a seguir:

Quando eu entrei no curso/ para mim era o seguinte:/ o licenciado é um biólogo que tem o diferencial de poder dar aula/ então eu entrei com essa concepção/ eu sou um biólogo que tem esse diferencial/ eu também posso dar aula (...) esse conteúdo que não é da educação ser o mesmo tanto para bacharel quanto para licenciado/ é que isso não te limita à carreira de professor/ eu não estou/ eu não estou limitada a dar aula. (Ester)

Nas narrativas dos nossos sujeitos, observamos também que há um grupo minoritário de professores, responsáveis por alguns dos Laboratórios de Ensino, que são preocupados e comprometidos com a formação docente e que são identificados como referências para a licenciatura. A esse grupo chamaremos Antigrupo pró-docência, um actante que promove uma associação com a identidade docente. Relembrando Latour (2012), na produção de conhecimento não há grupos, apenas inúmeras formações de grupos e alistamentos em grupos contraditórios. Para todo grupo há um antigrupo, que alimenta as controvérsias em torno do tema estudado. Ele afirma que um pesquisador da Teoria Ator-Rede tem o objetivo de seguir os traços deixados pela formação de grupos, pois estas formações deixam mais traços que as conexões já estabelecidas.

Veja os traços deixados por este antigrupo:

Os poucos [Laboratórios de Ensino] bons que a gente tem/ eles são tão proveitosos que a gente pode usar para todas as disciplinas/ porque a gente fez laboratório de botânica/ que pode ser usado para todos/ a gente aprendeu a fazer plano de aula/ 
que são coisas básicas para saber/ para dar aula/ eu acho que realmente se a gente não pusesse o pé no laboratório de botânica ia ficar complicado. (Maria).

Além de se constituir como um antigrupo minoritário percebe-se que alguns Laboratórios de Ensino realizam associações essenciais para a formação dos licenciandos. Isso fica explícito na fala de Maria: "Se a gente não pusesse o pé no Laboratório (de Ensino) de Botânica ia ficar complicado". Por esse motivo eles são um ponto de passagem obrigatório, uma vez que são considerados indispensáveis para a boa formação do professor, como vimos na fala de Maria.

Além das considerações que fizeram sobre o ICB como espaço formativo durante a graduação, os licenciandos também criticaram a Universidade, que age supervalorizando a pesquisa em detrimento do ensino e extensão. A Universidade aparece, portanto, como um ator que realiza translações que desviam o interesse dos licenciandos pela docência. Zélia conta que desenvolveu um material didático quando era monitora da disciplina de Citologia e Histologia Geral e o apresentou em um Encontro de divulgação de ações de ensino, pesquisa e extensão da Universidade:

(...) ganhei menção honrosa pelo projeto que eu apresentei/ foi muito legal/ foi muito gratificante/ e tudo/ mas/ é/ dentro dos projetos de monitoria/ de extensão e de iniciação científica/ cinco projetos de iniciação científica ganharam prêmio/ de dinheiro./ Se não me engano foram 500 ou 1000 reais/ cada aluno de iniciação científica/ e o de extensão e de monitoria/ nada./ Quem ganhou menção honrosa dentro da iniciação científica:/ cinco ganharam,/ da extensão/ zero,/ da monitoria/ zero/ ganhou a menção honrosa./ Toma aqui seu papel/ entendeu? Eu vejo que eles valorizam muito mais isso (...) (o valor) é muito maior para a pesquisa do que para os outros pilares da universidade. (Zélia)

O exemplo de Zélia é bastante ilustrativo do investimento desigual que recebem a Extensão e o Ensino, quando comparados à Pesquisa. A falta de investimento (inclusive financeiro) nas atividades relacionadas à docência é um efeito do prestígio das atividades de pesquisa na universidade, ator que age na rede identitária, desviando o interesse dos alunos pelo magistério.

Neste ponto do grupo focal achamos interessante destacar o seguinte diálogo, entre Maria, Ronaldo e Elisa:

A gente vem para a FaE/ e/ faculdade de educação/ o objetivo é a educação no ensino básico/ só que os professores que a gente tem contato/ eles têm o pezinho muito longe do ensino básico/ eu acho que eles nunca pisaram em uma escola/ eu não posso dizer todos né/ mas a maioria/ parece que eles nunca pisaram em uma escola/ então tudo que eles falam sobre escola para a gente/ é uma coisa tão longe da realidade que não é proveitoso. (Maria)

Se os próprios professores da $\mathrm{FaE}$ não derem para a gente uma visão um pouco otimista da coisa/ se eles confirmarem a visão pessimista/ aí ninguém forma/ ninguém. (Ronaldo) 
Mas não que eles são otimistas/ é a distância mesmo/ele não têm nem a otimista nem a pessimista/ é tipo/ eu desconheço sobre o que eu estou falando/ eu sou especialista nisso/ eu não conheço. (Maria)

Se eles não tentarem dar uma modificada/ uma incentivada na gente para seguir a área/ aí todo mundo desiste. (Ronaldo)

Vocês concordam que os professores da $\mathrm{FaE}$ são mais pesquisa que ensino/ eles são completamente pesquisa/ não são ensino. (Maria)

É a mesma coisa que o ICB. (Elisa)

É/ e é uma instituição/ de ensino. (Maria)

Este trecho do grupo focal nos parece de especial relevância, pois, surpreendentemente, evidencia a Faculdade de Educação como um ator-rede contra identidade. Quando afirmam que os professores desconhecem o contexto da escola básica, sobre o qual ensinam, e que, assim como no ICB, também na FaE a pesquisa é mais valorizada que o ensino, os licenciandos percebem contradições entre sua formação e o papel que se espera de uma faculdade de educação - valorizar o ensino. Assim, destacamos no ator-rede FAE, os actantes Professores formadores, que surpreendentemente agem desvalorizando o ensino em detrimento da pesquisa, e com isso desviando o interesse dos licenciandos pela docência.

Os licenciandos ainda apontam que as disciplinas da FAE agem, desviando o interesse pela docência, pois oferecem muita teoria e pouca prática, além de apresentarem conteúdos sobrepostos em mais de uma disciplina. Podemos verificar isso nas seguintes falas:

Você olha lá no currículo/ didática de ensino/ beleza/ vou aprender alguma coisa/ e você fica lendo texto. (Ester)

E fazendo Seminário (...) porque a gente tem muita matéria que deveria dar um suporte maior/ mas aí as didáticas ficam discutindo texto/ aí no outro semestre eles dão outro texto/ mas o assunto é o mesmo/ a discussão em sala de aula é a mesma. (Elisa)

Em seguida, os licenciandos demonstraram que gostariam de continuar a discussão e apontaram várias críticas ao Estágio Supervisionado, ator que também age realizando translações que desviam o licenciando da docência. Para eles o estágio tem a carga horária mal distribuída e deveria ser antecipado na matriz curricular. Novamente o currículo é apontado como um ator que não favorece a identidade docente:

Ele [o estágio] tinha que ser antes/ para a gente saber direito o que a gente está estudando/ para quê/ assim. (Efigênia)

Os licenciandos também comentaram sobre as fraudes no estágio e sobre o desestímulo para seguir a docência vindo dos próprios professores que atuam na escola: 
Eu cheguei para eu fazer estágio na escola que eu estudei no ensino fundamental/ e os professores falaram assim/ minha filha o que você está fazendo aqui/ alguns me deram aula/ vai embora/ escolhe outro curso/ desiste disso logo. (Zélia)

Conforme observamos, os professores atuantes, que recebem os estagiários na escola, agem de forma a desviar o interesse dos licenciandos na construção de uma identidade com a docência. A figura 3 ilustra uma possível representação dos actantes que agiram na rede identitária docente durante a formação acadêmica dos licenciandos.

Por conter mais actantes que desviam os licenciandos da docência do que actantes que se associam a ela, chamaremos esta rede de "contraidentitária" docente. Observe que, em comparação com as outras redes, referentes aos outros momentos do curso, esta é bem mais complexa e contém um número maior de actantes e conexões. Note também que a partir do ator licenciandos partem conexões para os actantes CRBio, Universidade, FAE, ICB e antigrupo pródocência. Este último é o único ator que realiza associações com a identidade docente. Todos os outros actantes agem realizando desvios em relação à docência. $\mathrm{O}$ ator Pesquisa mantém conexões com a Universidade, FAE e ICB, o que o coloca como ponto de passagem obrigatório na rede contraidentitária que traçamos.

FIGURA 3 - Actantes que agiram na rede identitária docente durante a trajetória acadêmica dos licenciandos

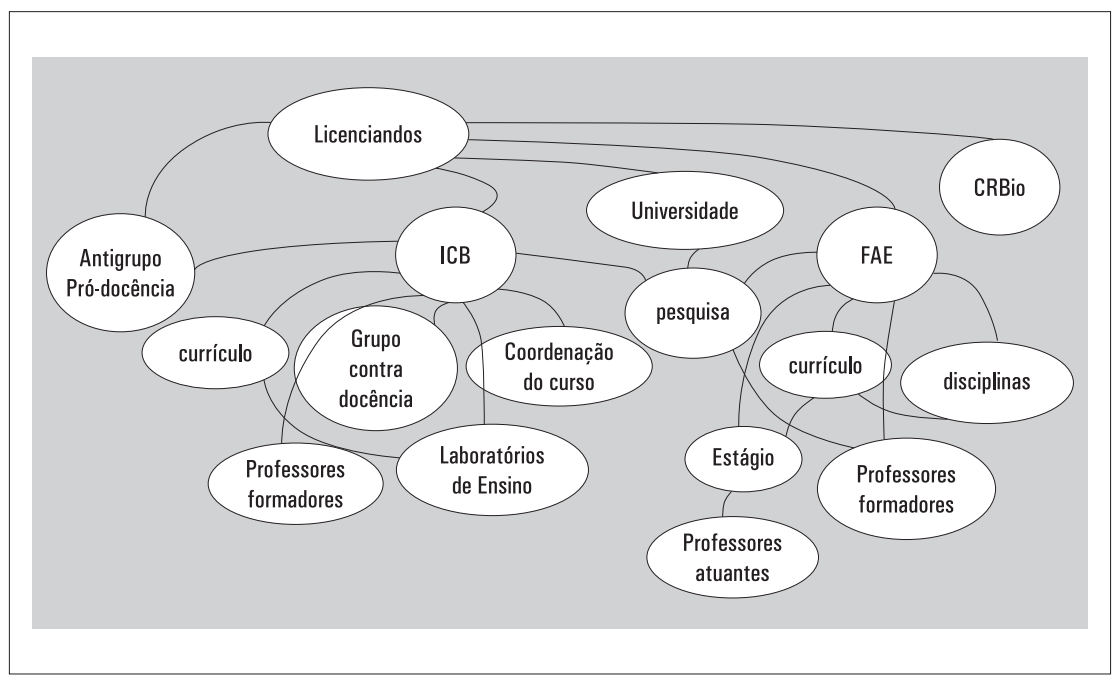

Para sintetizar os desvios e associações realizadas pelos actantes rastreados nas falas dos licenciandos, apresentamos o diagrama de translações da rede identitária ao longo do tempo: 
FIGURA 4 - Diagrama de translações relativas à identidade docente dos licenciandos.

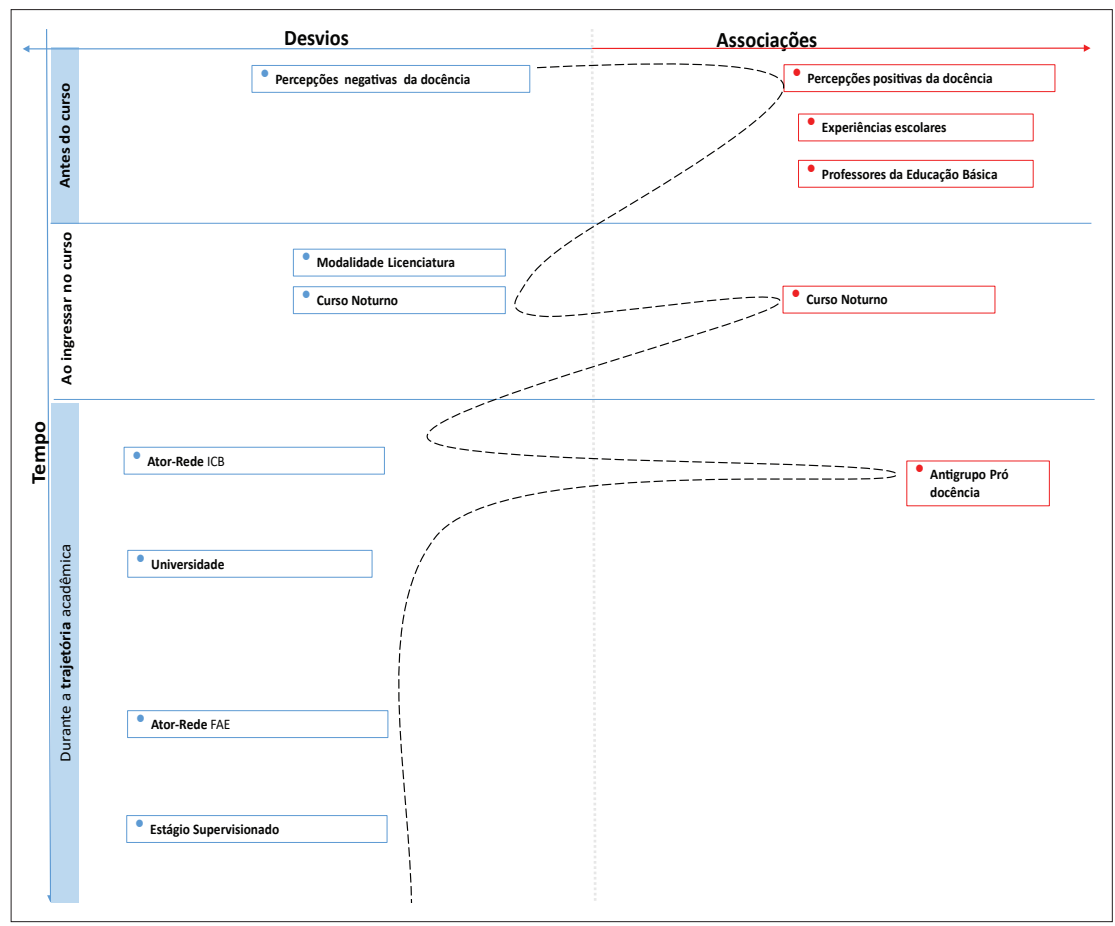

Os números no interior do diagrama representam actantes identificados nas falas dos licenciandos. Os atores-rede são agrupamentos de atores. O lado direito do diagrama representa as associações enquanto o esquerdo representa os desvios. Os actantes foram apresentados de acordo com o momento da trajetória de formação dos licenciandos, ou seja: "antes do curso", "ao ingressar no curso" e "durante a trajetória acadêmica". O tracejado se desloca ao longo da trajetória acadêmica dos licenciandos, e sua direção indica as associações e os desvios realizados pelos actantes que atuam ao longo desta trajetória.

Nota-se que os desvios em relação à docência crescem à medida que os licenciandos avançam na trajetória acadêmica, sendo mais numerosos durante o curso, quando, em tese, as associações deveriam ser mais abundantes, em se tratando de um curso de licenciatura. Por outro lado, observa-se que as associações em favor da docência, simbolizadas pelos quadros deslocados à direita no plano cartesiano, são escassas. No entanto, a associação criada em torno do Antigrupo pró-docência é representada por um deslocamento maior para a direita, o que pode indicar a força deste grupo minoritário na 
construção da identidade docente. Isso se dá em função deste grupo ser, na opinião dos licenciandos, indispensável para a formação de professores, isto é, um ponto de passagem obrigatório.

\section{O MAPEAMENTO DA REDE IDENTITÁRIA E CONTRAIDENTIRÁRIA DOCENTE E OS MUNDOS POSSÍVEIS}

Em nossa pesquisa fazemos uso da ideia de que a TAR fornece uma metodologia eficiente para mapear os interesses em jogo em uma dada situação, inventariando os actantes e suas associações, e apontando as opções em torno das quais é possível se (re)pensar e se (re)fazer as realidades. Ao realizarmos este mapeamento, fazemos um esforço de captar o movimento dos actantes, destes às redes, das redes aos cosmos e dos cosmos aos mundos possíveis (LATOUR, 2015).

Callon et al. (2001) afirmam que as situações de mundo são definidas pela listagem de entidades humanas e não-humanas que as compõem e pelas interações entre estas entidades. "Na escolha de um estado possível do mundo, ou seja, no processo de tomada de decisão, escolhemos as entidades com as quais decidimos viver e o tipo de história que gostaríamos de compartilhar com elas" (CALLON et al., 2001, p. 20).

Venturini (2010) ressalta que grupos e antigrupos são formados em função de suas ideologias. Para o autor, as ideologias não são descrições do mundo como ele é, mas visões do mundo como ele poderia ser. Em suas palavras: "Enquanto a vida coletiva é caótica e errática, ideologias são ordeiras e harmoniosas. Elas não são universos, mas cosmos" (VENTURINI, 2010, p.10). Repensar os cosmos significa, portanto, pensar em utopias, em mundos possíveis. Ressalta-se, entretanto, que pensar em mundos possíveis não implica sustentar uma visão ingênua de um mundo com interesses comuns, sem conflitos ou disputas.

Nossos diagramas e redes sintetizam cosmos: as associações e os desvios ocorridos no percurso de identificação dos sujeitos pesquisados com a licenciatura. As redes e diagrama que traçamos são ferramentas que expressam os interesses em jogo na construção de cosmos para a identidade docente. Por exemplo, quando os licenciandos afirmam que o currículo do curso não é integrado, queixam-se da formação de seus professores, da desvalorização da licenciatura e da docência em detrimento da pesquisa e colocam problemas em diferentes práticas formativas, estão apontando as composições de interesses que estão agindo na sua formação inicial. Tais composições - as translações - incidem diretamente na (falta de) identificação que têm com o magistério. 
Mas, quais seriam as contribuições deste trabalho para melhorar esta situação? Ao utilizarmos a TAR como uma metodologia para o mapeamento de situações complexas, nós argumentamos que cartografia de controvérsias pode ser uma ferramenta bastante útil para o delineamento dos cosmos e a proposição de estados possíveis de mundo, ajudando-nos a pensar em políticas púbicas, em reformas para os cursos de licenciaturas e na valorização destes cursos nas universidades.

\section{REFERÊNCIAS}

ARAÚJO, W. S.; ÁVILA, D. A.; FALEIRO, F. A. M. V.; COSTA, R. M. Formação acadêmica e identidade profissional de formandos do curso de Ciências Biológicas do ICB/UFG. Revista Solta a Voz, v. 18, n. 2, p. 243-254, 2007.

ARAUJO, R. S.; VIANNA, D. A carência de professores de ciências e matemática na Educação Básica e a ampliação das vagas no ensino superior. Ciência \& Educação, v.17, n. 4, p. 807-822, 2011.

BARBOUR, R. Grupos Focais. Porto Alegre: Artmed, 2009.

BLOK, A.; JENSEN, T. E. Bruno Latour: hybrid thoughts in a hybrid world. London: Routledge, 2011.

CALLON, M.; LASCOUMES, P.; BARTHE, Y. Acting in an uncertain world: An essay on technical democracy. Paris: Seuil, 2001.

CASTRO, S. M. V.; BRANDÃO, Z.; NASCIMENTO, I. P. Biólogo ou professor de Biologia: um estudo entre estudantes do curso de Licenciatura em Ciências Biológicas. In: Congresso Nacional de Educação - X EDUCERE. Anais... Curitiba, nov. 2011.

CERQUEIRA, S. V. S. C.; CARDOSO, L. R. Biólogo-professor: relação entre expectativas profissionais e concepções em torno da docência para licenciandos em Ciências Biológicas. Contexto \& Educação, n. 84, p. 143-160, jul./dez. 2010.

DINIZ PEREIRA, J. E. Formação de professores: pesquisas, representações e poder. Belo Horizonte: Autêntica Editora, 2000.

LATOUR, B. Como falar do corpo. In: NUNES, J.A; ROQUE, R. (org.). Objectos impuros: experiências em estudos sociais da ciência. Porto: Edições Afrontamento, p. 39-61, 2008.

LATOUR, B. Reagregando o Social. Uma introdução à teoria ator-rede. Salvador/ Bauru: EDUFBA/EDUSC, 2012.

LATOUR, B. Scientific Humanities. France Université Numeriquè. Massive Open Online Course (MOOC), jan.-mar. 2015. Disponível em: https:/ / www.france-universite-numeriquemooc.fr/courses/FUN/. Acesso em: 15 mar. 2015.

LIBÂNEO, J. C. Organização e gestão da escola. Goiânia: Alternativa, 2001.

MORAES, R. Análise de conteúdo. Educação. v. 22, n.37, p.7-32, 1999.

NESPOR, J. Knowledge in Motion: Space, Time and Curriculum. In: Undergraduate Physics and Management. Knowledge, Identity and School Life Series. London and Washington, D.C.: Ed. Falmer Press, 1994.

PIMENTA, S. G. Formação de professores: identidade e saberes da docência. In: PIMENTA, S. G. et al. (org.). Saberes pedagógicos e atividade docente. $4^{a}$ ed. São Paulo: Cortez. p. 15-34, 2005. 
ROCHA, L. D. Avaliação do curso de licenciatura em Ciências Biológicas da UNIFAL-MG na perspectiva de seus egressos. Revista Profissão Docente, Uberaba, v.13, n. 28, p.76-98, jan/jun 2013.

VENTURINI, T. Diving in magma: how to explore controversies with actor-network theory. Public Understanding of Science, Londres, v. 19, n. 3, p 258-273, 2010.

VENTURINI, T; RICCI, D.; MAURI, M.; KIMBELL, L.; MEUNIER, A. Designing Controversies and their Publics. Design Issues, v. 31, n. 3. 2015. Disponível em: http:// www.tommasoventurini.it/wp/?cat=9. Acesso em: 07 mai. 2015.

\section{NOTAS}

${ }^{1} \mathrm{O}$ termo ator (ou actante) deriva do trabalho semiótico de Algirdas Greimas, segundo o qual qualquer palavra é definida completamente em termos de suas relações a outros termos linguísticos. Latour estende e aplica essa visão relacional a todos os tipos de entidades (materiais, atores humanos, eventos, etc.). Por isso, a TAR também é conhecida como semiótica material (BLOCK; JENSEN, 2011, p. 17 e 167).

${ }^{2} \mathrm{O}$ uso que fazemos do termo ator-rede, aqui, é meramente didático, tendo em vista que "em uma controvérsia, qualquer ator pode se decompor em uma rede frouxa e qualquer rede, não importa o quão heterogênea seja, pode ser aglutinada para funcionar como um ator" (VENTURINI, 2010, p. 262).

Submetido: 06/06/2016

Aprovado: 17/11/2017

Contato:

Luciana Resende Allain

Caixa Postal 57

Diamantina $|\mathrm{MG}|$ Brasil

CEP 39.100-000 